\title{
COMPARATIVO DO USO DAS TICS NA EDUCAÇÃO SUPERIOR BRASILEIRA E CHILENA
}

\section{COMPARATIVE USE OF ICTS IN BRAZILIAN AND CHILEAN HIGHER EDUCATION}

Francisco Rodrigues da Silva Neto ${ }^{1}$; Erick Viana da Silva ${ }^{2}$; Kilma da Silva Lima Viana $^{3}$

\section{INTRODUÇÃO}

Diante o surgimento das novas gerações, podemos observar as mudanças na maneira de se viver no dia-a-dia. Uma vez que, os jovens dos dias atuais, têm uma maior facilidade de se habituar e manusear as tecnologias disponíveis para si. Com essas mudanças, podemos encontrar diversos aspectos que dificultam a aplicabilidade das tecnologias no dia-a-dia e não seria diferente na educação.

Esse trabalho apresentará um comparativo das diferenças da aplicação das tecnologias na educação superior do Brasil e do Chile. Através da experiência de intercâmbio realizada no ano de 2017, através do Programa Internacional Despertando Vocações para as Licenciaturas, (PDVL).

\section{RELATO DE EXPERIÊNCIA}

No segundo semestre de 2017, pude realizar um intercâmbio para Universidad Tecnológica de Chile - INACAP. Onde tive a experiência de estudar em imersão em outra cultura. De início consegui sentir a diferença organizacional do país, apenas ao chegar no aeroporto e me deslocar para residência onde passei o período de intercâmbio. Antes do início das aulas pude conhecer um pouco da cultura chilena na cidade de Santiago, e foi possível observar a preservação cultural com sua dança chamada "cueca" e a questão organizacional do país, desde a distribuição física da cidade, englobando as ferrovias e estradas, até a educação da população.

A experiência que vivi no Chile foi ímpar em minha vida. Tive a oportunidade de conhecer formas de processos educativos diferenciados do que eu vivenciei e vivencio no Brasil. O que me chamou a atenção foi a utilização das TICs na educação do Chile. Observei o quanto eles apresentam estrutura para tal. Com laboratório e repositórios online. As TICs, no Chile, aparecem como alternativa para facilitar, aprimorar e a somar junto a educação,

\footnotetext{
${ }^{1}$ Licenciatura em Química, IFPE, silvanetofr@outlook.com

${ }^{2}$ IFPE, erick.viana@ vitoria.ifpe.edu.br

${ }^{3}$ IFPE, kilma.viana@ vitoria.ifpe.edu.br
} 
principalmente com a inserção dos computadores no contexto escolar, enriquecendo o acesso à informação. (CAMILLO, 2018).

Uma das alternativas que o INACAP utiliza para a inclusão das TICs, é o uso constante de sua plataforma online, fazendo com que a mesma seja extremamente necessária no dia-adia dos alunos. E mais importante que isso, é dar condições aos estudantes terem acesso a rede de comunicação.

Ressalta-se a importância de um bom planejamento para a utilização das TICs. Não basta utilizá-la apenas como substituta da caneta e papel ou usar a internet para pesquisa no google. Para que a sua utilização seja efetiva, faz-se necessário que os estudantes, além de terem as máquinas em boas condições, a internet rápida, também um diálogo entre o que se aprende em sala de aula e a real necessidade de uso das TICs e para isso, um repositório com ferramentas que auxiliam na aprendizagem.

Minha experiência no Brasil com TICs em sala de aula, limitou-se a atividades de pesquisa, sem orientações mais detalhadas de sites na área. Muitas vezes, o preparo do professor em utilizar e orientar os estudantes nas plataformas disponíveis também foram limitados. Além disso, o número de computadores é insuficiente para os estudantes ou o uso dos laboratórios de informática, muitas vezes, é limitado às aulas de informática e não são abertos aos estudantes para atividades relevantes, que auxiliassem no processo de aprendizagem. Essa realidade dificulta o uso efetivo das TICs, uma vez que para incrementar a tecnologia necessita-se de aparatos tecnológicos e um aperfeiçoamento dos profissionais da área.

\section{CONSIDERAÇÕES}

Através dessa experiencia pude observar a importância de sairmos de nosso "mundo" e conhecer novas formas de sociedade. Mesmo sendo países da América Latina, mesmo sendo vizinhos e com diversos aspectos semelhantes, foi possível entender também formas diferentes de educação, que eu ainda não havia experimentado. 
Essa experiência foi importante para mim, pois hoje olho a minha instituição com outros olhos, consigo ver as suas potencialidades e também suas limitações. Pude aprender a estudar de outra forma e ter um olhar mais crítico, no melhor sentido da palavra, e entender que para consolidar o uso das TICs na educação, faz-se necessário um processo de reeducação e aperfeiçoamento dos profissionais. Não apenas deixando disponível a tecnologia sem que seja feito estudos para seu uso correto.

\section{REFERÊNCIAS}

CAMILLO, Cíntia Moralles; MEDEIROS, Lisiany Muller. Educação do campo e suas práticas educativas: a tecnologia em prol da formação de educadores. Simpósio Tecnologia e Educação a Distância no Ensino Superior, v. 1, n. 1, 2018. 